\title{
TU/e EmonONEN

\section{Analysis and initial synthesis of a novel linear actuator with active magnetic suspension}

\section{Citation for published version (APA):}

Lebedev, A., Lomonova, E. A., Leuven, van, P. G., Steinberg, J., \& Laro, D. A. H. (2004). Analysis and initial synthesis of a novel linear actuator with active magnetic suspension. In Industry Applications Conference : Proceedings of the 39th IAS Annual Meeting, 7-10 October 2004, Seattle (pp. 2111-2118). Institute of Electrical and Electronics Engineers. https://doi.org/10.1109//AS.2004.1348758

DOI:

10.1109/IAS.2004.1348758

Document status and date:

Published: 01/01/2004

\section{Document Version:}

Publisher's PDF, also known as Version of Record (includes final page, issue and volume numbers)

\section{Please check the document version of this publication:}

- A submitted manuscript is the version of the article upon submission and before peer-review. There can be important differences between the submitted version and the official published version of record. People interested in the research are advised to contact the author for the final version of the publication, or visit the $\mathrm{DOI}$ to the publisher's website.

- The final author version and the galley proof are versions of the publication after peer review.

- The final published version features the final layout of the paper including the volume, issue and page numbers.

Link to publication

\section{General rights}

Copyright and moral rights for the publications made accessible in the public portal are retained by the authors and/or other copyright owners and it is a condition of accessing publications that users recognise and abide by the legal requirements associated with these rights.

- Users may download and print one copy of any publication from the public portal for the purpose of private study or research.

- You may not further distribute the material or use it for any profit-making activity or commercial gain

- You may freely distribute the URL identifying the publication in the public portal.

If the publication is distributed under the terms of Article $25 \mathrm{fa}$ of the Dutch Copyright Act, indicated by the "Taverne" license above, please follow below link for the End User Agreement:

www.tue.nl/taverne

Take down policy

If you believe that this document breaches copyright please contact us at:

openaccess@tue.nl

providing details and we will investigate your claim. 


\section{Analysis and initial synthesis of a novel linear actuator with active magnetic suspension}

\author{
Anton V. Lebedev, Elena A. Lomonova, Peter G. van \\ Leuven, Joris Steinberg \\ Electrical Engineering Department \\ Eindhoven University of Technology \\ Eindhoven, The Netherlands \\ a.lebedev@tue.nl
}

\author{
Dick A.H. Laro \\ Mechanical Engineering Department \\ Delft University of Technology \\ Delft, The Netherlands \\ d.a.h.laro@wbmt.tudelft.nl
}

\begin{abstract}
In this paper attention is given to the initial design and experimental verification of the novel IU-shaped electromechanical actuator as a part of six degrees of freedom (6DoF) contactless sliding system. Such a synergetic system is reached by integration of electromagnetic and mechanical structures of magnetic bearing and linear electromechanical actuator. Initially the performance of the electromagnetic module is examined. An analytical investigation of decoupled forces, originated from permanent magnets and suspension coils as functions of rotor position and current values in the control coils, is performed. Numerical results (the FEM models - Maxwell 3D Ansoft Co.) are validated by static measurements. Initial geometry is modified to demonstrate the improvement of the actuator performance.
\end{abstract}

Keywords-actuators, finite element methods; magnetic forces; magnetic levitation; magnetostatics; soft magnetic materials

\section{INTRODUCTION}

An IU-shaped electromechanical actuator is a part of a new linear slider system (Fig. 1) for six degrees of freedom (6 DoF) suspension and propulsion described in $[1,2]$. This system is tailored for optical discs mastering applications and should provide the movement along one long stroke sliding direction while being stabilized in other directions.

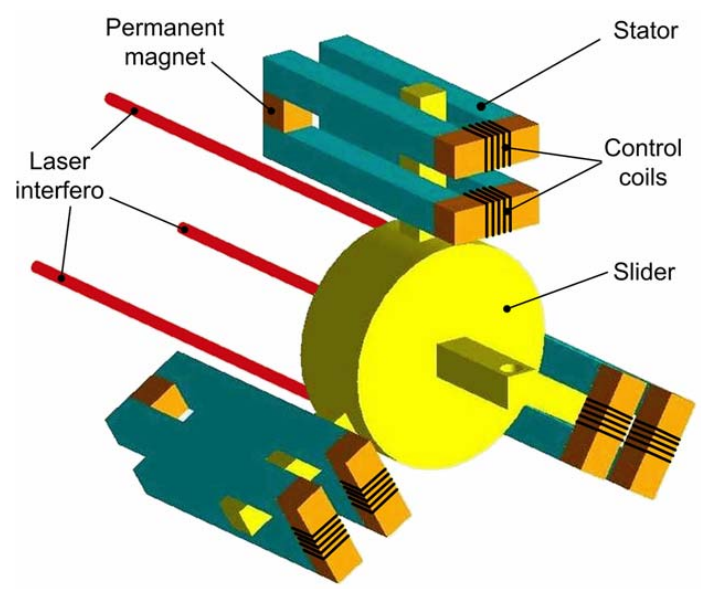

Figure 1. Six Degree-of-Freedom Electromagnetic Contactless Slide System.
From electromechanical and control points of view such an apparatus (the system combines the linear actuator providing a bi-directional movement along $x$-axis and permanent magnet biased active magnetic bearings) belongs to the class of nonlinear high-order dynamic systems of considerable complexity. It is amenable to a formal mathematical analysis. However, it is not a trivial matter to comprehend the principles of its operation, e.g. under static and transient conditions, in an imaginative way.

The general view of the IU-actuator is shown in Fig. 2. A stator consists of two identical U-shaped iron parts spaced from each other and magnetically coupled by means of two permanent magnet bars (for the biasing purposes) with the same direction of magnetization (along the $y$-axis) in upper and lower branches. The magnets' driven fluxes (Fig. 2) travel along the stator core legs (the upper and lower ones), cross the air gaps, both enter and pass through the rotor length, return across the two next air gaps and stator yokes to the magnets. Both U-shaped parts are supported (connected) by vertical iron legs, suspension coils controlling the suspension of the I-rotor are wounded around each of them.

The fluxes produced by two suspension coils travel along the upper (right and left ones) stator cores, cross the air gaps and pass through the rotor and return across the two next air gaps and lower stator yokes.

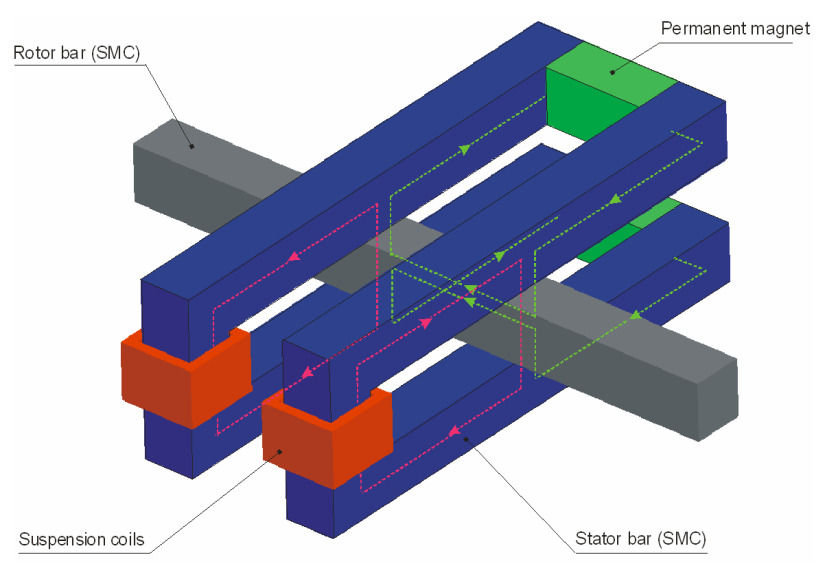

Figure 2. IU-shaped actuator topology with indicated main flux paths. 
Four propulsion coils (Fig. 3) are placed consequently around each long iron bar (two upper and two lower stator bars). A rotor (mover) is inserted in the clearance between halves of the U-shaped stator parts. The rotor includes no field sources. All resulting forces acting on the rotor are reluctance forces, caused by the permanent magnets and the suspension coils, and the Lorenz forces caused by the propulsion coils.

Usually, in magnetically levitated systems the role of the biasing is to improve the linearity and dynamic performance. In this paper practical application of a biasing scheme, based on incorporating permanent magnets (PMs) into the magnetic structure, is reported. The primary advantage of this scheme is a reduction in electrical power consumption. The magnetic flux, created by the upper permanent magnets (Fig. 3 green arrows) crosses the two upper air gaps that causes reluctance forces $\left(F_{z \text {-upper-right }}, F_{z \text {-upper-left }}\right)$ in both air gaps between two upper stator bars and rotor (mover). The magnetic flux from the lower PMs causes reluctance forces $\left(F_{z \text {-lower-right }}, F_{z \text {-lower-left }}\right)$ in both air gaps between two lower stator bars and rotor (mover). These magnetic fluxes are called bias fluxes.

To be able to control the reluctance forces on the mover (rotor), two additional coils are placed at the ends of stator legs and the extra (control) forces are generated (Fig. 3 red arrows). These control forces are dependent on the applied current and rotor position. The total suspension force acting on the rotor is the sum of the reluctance forces and the control forces. It has a small $x$-component in the direction of motion (propulsion) and a significant suspension force ( $z$-component) along a vertical axis.

Horizontal position of the rotor bar is controlled by the propulsion coils. Propulsion principle is based on the interaction between the magnetic fluxes crossing the air gaps and the currents in the propulsion coils that cause the Lorenz forces acting on the rotor along the $x$-direction (Fig. 3 blue arrows). Obviously, the electromagnetic field generated by the propulsion coils distorts the distribution of the flux density in the stator bars and generates additional reluctance forces.

The $y$-component of the forces is neglected, as it remains very small with respect to the other $x$ - and $z$-force components.

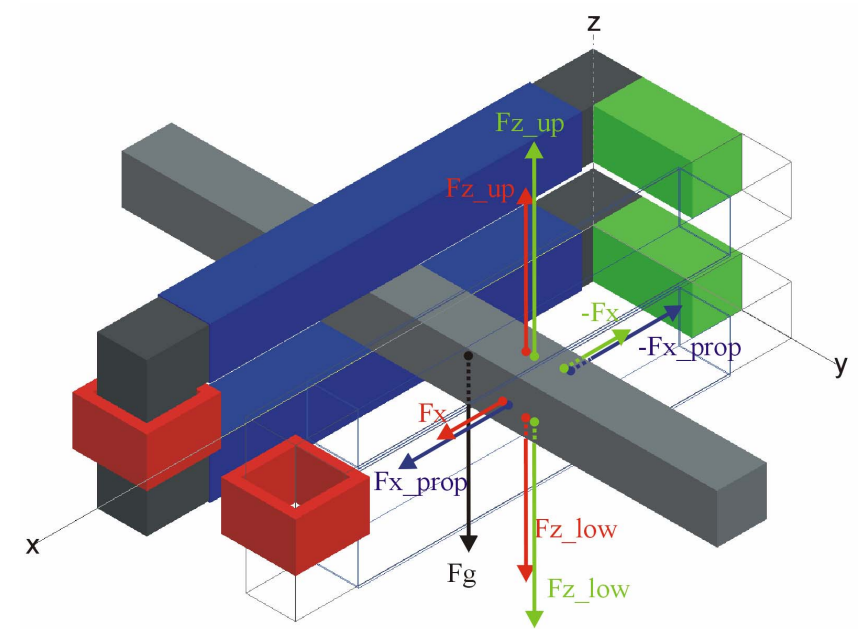

Figure 3. Forces acting on the rotor bar (colors of the arrows correspond to the colors of the electromagnetic field sources-PMs and coils.
As it follows from the Fig. 5 the field distribution possesses a three-dimensional nature. Besides, the large air gaps cause significant values of leakage fluxes. Thus, the analysis of the actuator is becoming very complex.

\section{PRELIMINARY ANALYSIS}

To prove the appropriateness of the proposed IU-shaped module for being used in the above described system, the magnetostatic analysis is performed. To simplify the study it is divided into several stages. The first step of investigation is to estimate the behavior of the actuator with the permanent magnets only. The profiles of the force dependencies versus the $z$ - and $x$-displacement of the rotor are obtained, and paths and values of the leakage fluxes are estimated. The same procedure, carried out for the IU-shaped module with PMs and suspension coils, forms the second step. The third, more complicated, stage is to study the actuators behavior with all three field sources. The two components of the total force acting on the rotor bar, namely $F_{x}$ and $F_{z}$, are used as design functions,. They are dependent on the actuator geometry, materials, current values in the coils and position of the rotor in the $x z$-plane. During the analysis it was assumed that torques around the $x$ - and $y$-axes are eliminated by the constructive arrangement of the total $6 \mathrm{DoF}$ system and torque around the $z$-axis can be controlled by the propulsion coils.

\section{A. Analytical approach}

For the simplest case of the IU-shaped actuator structure with only permanent magnets several different approaches are used for the force computation. First of all, a coarse analytical model is created utilizing the virtual displacement method. It allows a decoupled estimation of vertical suspension force $F_{z}$ resulting from permanent magnets and suspension coils. The calculation of electromagnetic forces by direct differentiation of the magnetic energy or coenergy is straightforward, and perfectly rigorous.

Generally, the force $f_{q}$ due to the presence of permanent magnets acting on a rotor bar in an arbitrary $q$-direction is equal to a derivative of coenergy $W_{c e}$ with respect to $q$ while the flux linkage $\psi$ is constant.

$$
\begin{aligned}
& f_{q}=-\left.\frac{\partial W_{c e}}{\partial q}\right|_{\Psi=c o n s t}=-\left.\frac{\partial}{\partial q}\left(\frac{1}{2} \cdot \Phi^{2} R_{m}\right)\right|_{\Psi=\text { const }}= \\
& =-\left.\left[\frac{1}{2} \Phi^{2} \frac{\partial R_{m}}{\partial q}+\Phi R_{m} \frac{\partial \Phi}{\partial q}\right]\right|_{\Psi=\text { const }}=-\left.\frac{1}{2} \Phi^{2} \frac{\partial R_{m}}{\partial q}\right|_{\Psi=\text { const }}
\end{aligned}
$$

where $\Phi$ is a flux created by permanent magnet and $R_{m}$ is total reluctance of magnetic circuit. The force $f_{q}$ due to the presence of control coils acting on a rotor bar in $q$-direction is

$$
\begin{aligned}
& f_{q}=-\left.\frac{\partial W_{c e}}{\partial q}\right|_{\Psi=\text { const }}=-\left.\frac{\partial}{\partial q}\left(\frac{1}{2} \cdot F^{2} \Lambda_{m}\right)\right|_{\Psi=\text { const }}= \\
& =-\left.\left[\frac{1}{2} F^{2} \frac{\partial \Lambda_{m}}{\partial q}+F \Lambda_{m} \frac{\partial F}{\partial q}\right]\right|_{\Psi=\text { const }}=-\left.\frac{1}{2} F^{2} \frac{\partial \Lambda_{m}}{\partial q}\right|_{\Psi=\text { const }}
\end{aligned}
$$


where $F$ is magnetomotive force of the coil and $\Lambda_{m}$ is a total permeance of magnetic circuit.

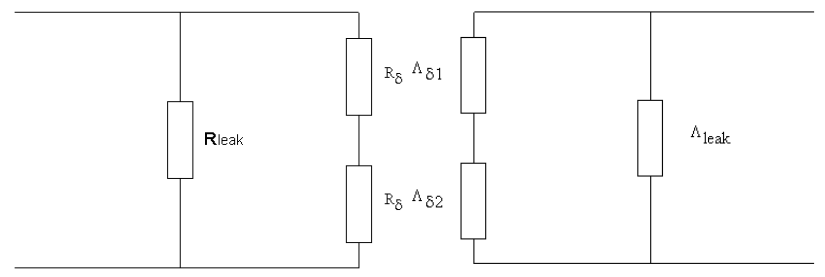

a)

b)

Figure 4. Equivalent magnetic circuits for decoupled force calculations: a) reluctance elements, b) permeance elements.

To determine the above mentioned total reluctance and permeance the corresponding simple equivalent magnetic circuits (Fig. 4 a, b) have being built taking into account the leakage fluxes and fringing effects based on FEM calculation results and [4]. An equivalent scheme represented in Fig. 4 a) is related to the flux originated from permanent magnet source and is associated with two horizontal circuits of the IU-actuator (green lines in Fig. 2). Fig. 4 b) represents the flux from another source (suspension coil) and is associated with vertical plane perpendicular to the rotor bar (red lines in Fig. 2).

The input reluctance and permeance of the corresponding equivalent circuits are

$$
\begin{gathered}
R_{m}=\frac{2 \cdot R_{\delta} \cdot R_{\text {leak }}}{2 \cdot R_{\delta}+R_{\text {leak }}}, \\
\Lambda_{m}=\frac{\left(\Lambda_{\delta 1}+\Lambda_{\delta 2}\right) \cdot \Lambda_{\text {leak }}}{\Lambda_{\delta 1}+\Lambda_{\delta 2}+\Lambda_{\text {leak }}}
\end{gathered}
$$

where index "leak" means a leakage through the permitted constructive clearance between stator bars, index $\delta$ is the air gap and indexes $\delta 1$ and $\delta 2$ are the upper and lower air gaps respectively. After substitution of the corresponding values of reluctances and permeances into (3) and (4) and further simplifications, the total reluctance and total permeance are derived as functions of the $z$-position $\left(R_{m}(z)\right.$ and $\left.\Lambda_{m}(z)\right)$.

The method for predicting the force distribution in IUshaped actuator and its governing equations are implemented in a form of a rapid computational tool in Mathcad, and simulation results are compared with FEM calculation results.

However, this simple decoupled approach does not show the interaction between the magnetic fields of the PMs and suspension coils and can not predict in a proper way the behavior of the actuator, for example, in case of partial saturation of the rotor or the stator bars. That was demonstrated by a more accurate FEM analysis and measurements on the test set-ups. A new analytical model taking into account the partial saturation of the stator and the rotor bars, leakage fluxes and cross-coupling effects between the suspension and the propulsion directions is currently under development $[7,9]$.
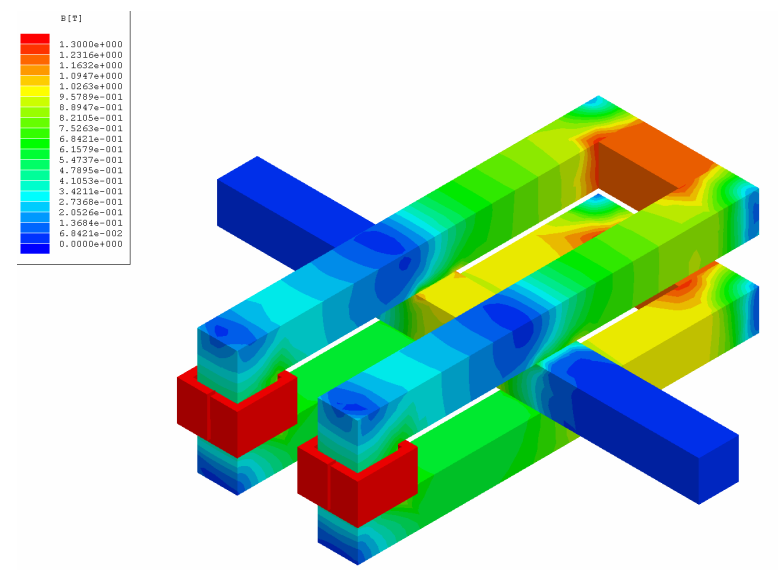

Figure 5. Field distribution in IU-shaped actuator with PMs and suspension coils introduced.

\section{B. FEM investigation}

Complicated nature (Fig. 5) of the field distribution caused by the 3D geometry and significant influence of the leakage fluxes make the analytical analysis of the actuator very difficult. The FEM magnetostatic calculations (Maxwell 3D Ansoft Co. [3]) are used for more accurate estimation of the field quantities and forces originated from the permanent magnets and the coils for the varied positions of the rotor along the $z$ - and $x$-axes, [10].

In Maxwell 3D Ansoft Co. the 3D FEM modification of the virtual work method (Coulomb virtual work method; [8]) is implemented. This method allows making a virtual displacement analytically. Considering the vector magnetic potential $(\bar{A})$ formulation of a $3 \mathrm{D}$ problem in Cartesian coordinates, the coenergy is a function of $\bar{A}, \bar{J}$ (current density) and coordinates $x, y, z$. Considering a virtual displacement in an arbitrary $q$-direction $(x, y$ or $z)$ and holding $\bar{J}$ constant

$$
\begin{array}{r}
f_{q}=\frac{\partial W_{e}^{\prime}}{\partial q}(A, q)=\left(\frac{\partial W_{e}^{\prime}}{\partial A} \cdot \frac{\partial A}{\partial q}\right)_{A \text { varying }}+ \\
+\left(\frac{\partial W_{e}^{\prime}}{\partial q}\right)_{A \text { constant }}
\end{array}
$$

It can be observed that the finite element method finds the distribution of $\bar{A}$ which makes $\frac{\partial W_{e}^{\prime}}{\partial A}=0$. Thus,

$$
f_{q}=\left(\frac{\partial W_{e}^{\prime}}{\partial q}\right)_{A \text { constant }}
$$


which can be obtained from a straightforward initial position field solution.

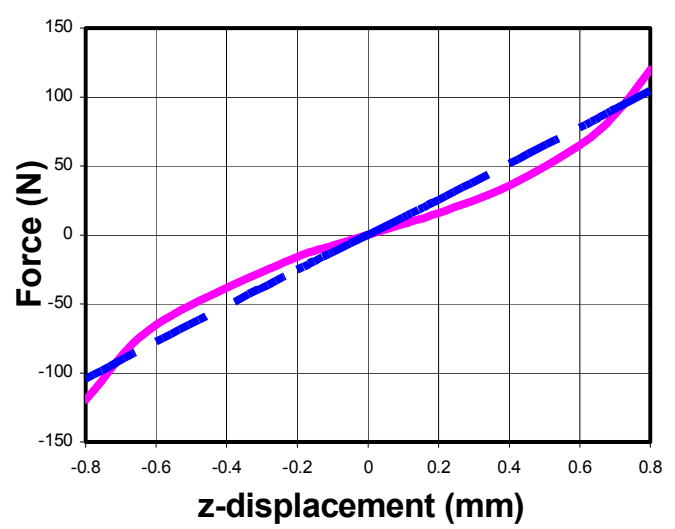

Figure 6. Analytical (--) and numerical (-) force profiles (originated by permanent magnets) dependent on the z-axis rotor position.

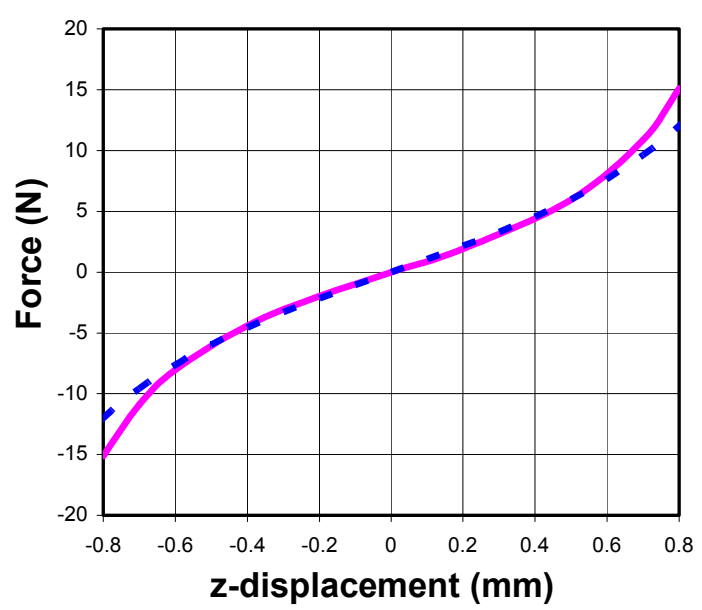

Figure 7. Analytical (--) and numerical (-) force profiles (originated by suspension coils) dependent on the $\mathrm{z}$-axis rotor position.

In Fig. 6 and Fig. 7 the comparison of the results obtained by analytical and numerical (FEM) calculations of the decoupled suspension forces created by the permanent magnets and the suspension coils is shown respectively.

During the FEM simulations the isotropic properties of the stator and the rotor bars material are considered (that is valid in case of the use, for example, of the SMC - Somaloy ${ }^{\mathrm{TM}} 500$, Höganäs AB; [6]). The calculations are carried out for a few permanent magnets configurations as well as for the different materials and positions of the rotor bar. The main sizes of the models, which are used for analytical, numerical and experimental studies, are presented in Table 1.

TABLE I. INITIAL GEOMETRY PARAMETERS OF THE IU-MODULE

\begin{tabular}{|c|c|}
\hline 4 stator bars & $20 \times 20 \times 200 \mathrm{~mm}^{3}$ (each) \\
\hline 1 rotor bar & $20 \times 20 \times 250 \mathrm{~mm}^{3}$ \\
\hline 2 suspension coil cores & $20 \times 20 \times 22.2 \mathrm{~mm}^{3}$ (each) \\
\hline
\end{tabular}

\begin{tabular}{|l|l|}
\hline Air gap height & $1.1 \mathrm{~mm}$ \\
\hline Permanent magnets & $63 \times 36 \times 10 \quad \mathrm{~mm}^{3}$ \\
\hline
\end{tabular}

The analytical expression for estimation of the $z$-force component assumes the flux, flowing through the working air gap, is perpendicular to the surfaces of the stator and rotor bars. Furthermore, the flux lines are assumed to be straight, while the permeability of the magnetic material is equal to infinity $\left(\mu_{S M C}=\infty\right)$ and the leakage flux value is constant. Only the reluctances or permeances of the working air gap are dependent on the $z$-position. FEM analysis shows that the main part of the flux does pass the working air gap in the above mentioned way (Fig. 8, Fig. 9). Therefore, a sufficient accuracy of the analytical $z$-force expressions is obtained for both the force originated from the permanent magnets and the force from the suspension coils (Fig. 6, Fig. 7).

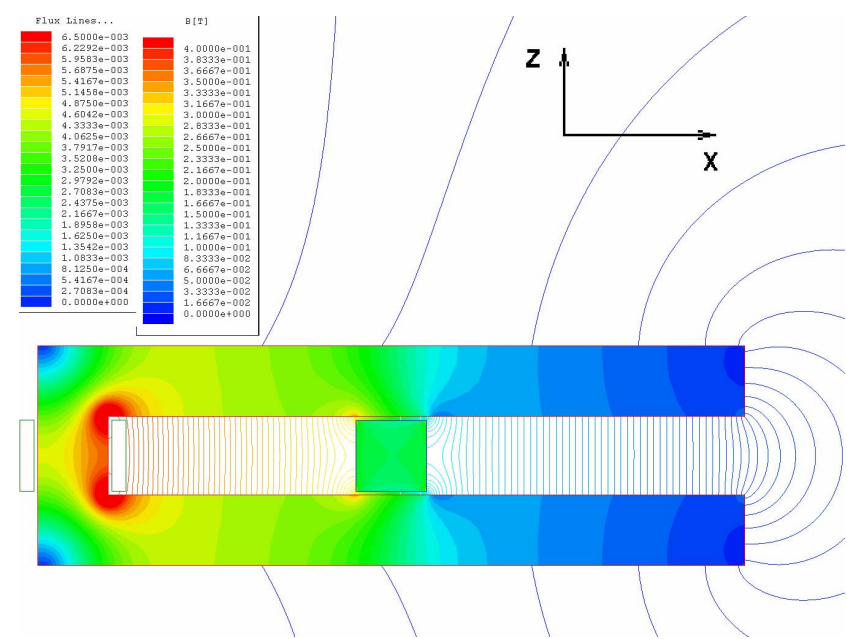

Figure 8. 2D field distribution in U-shaped part of the actuator originated from the suspension coil.

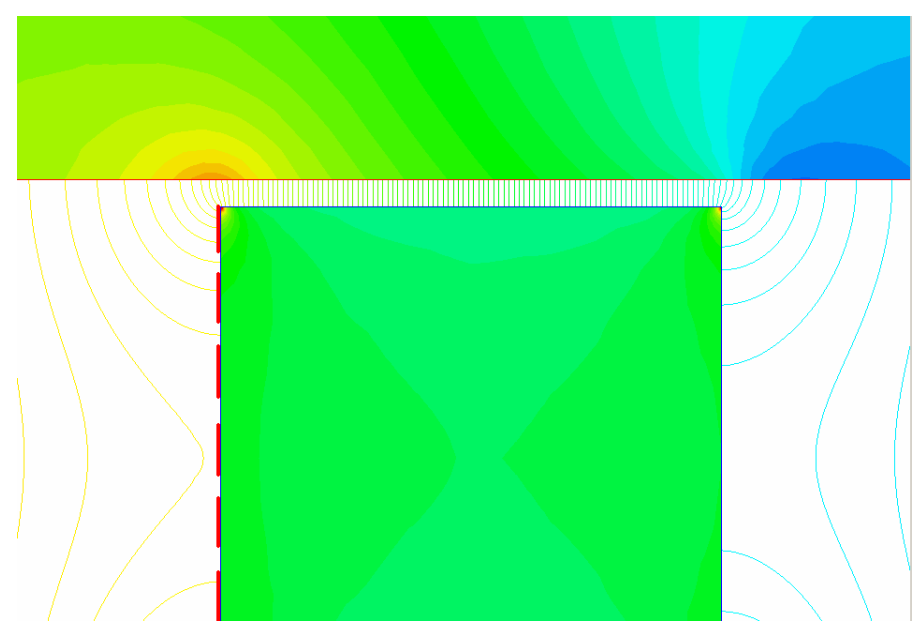

Figure 9. Zoomed 2D field distribution in the working air gap.

According to the virtual displacement principle the $x$-force can be determined analytically by (1) as well. The $x$-component of the force acting on the rotor is generated by the magnetic 
flux passing through the side face of the rotor (red dashed line in Fig. 9) and is actually a part of the leakage flux flowing through the constructive clearance between the two upper or the two lower stator bars. Additional permeances should be included in the equivalent circuit representing this part of the flux. However, the part of the magnetic flux entering the rotor in $x$-direction is significantly smaller than the one in $z-$ direction and even than the leakage flux. Besides, the shape of the air gap through which that part of the flux is passing is nontrivial due to the fringing effect. This inhibits the creation of an equivalent circuit for the analytical determination of the $x-$ force. Several topologies of equivalent circuits being investigated are proven to be of insufficient accuracy. This makes the FEM models very important on the initial stage of the development.

\section{SYNTHESIS OF THE GEOMETRY}

This subsection describes the peculiar design choices concerning the UI-module geometry leading to an improved electromagnetic performance.

\section{A. Specifications}

Starting point in the design is determining the set of specifications. The following specifications are required for the total 6 DoF positioning system:

$\begin{array}{ll}\text { Suspended mass } & 1 \mathrm{~kg} \\ \text { Acceleration in propulsion direction } & 10 \mathrm{~m} / \mathrm{s}^{2} \\ \text { Positioning range (x direction) } & 50 \mathrm{~mm} \\ \text { Propulsion bandwidth } & 400 \mathrm{~Hz} \\ \text { Suspension bandwidth } & 400 \mathrm{~Hz}\end{array}$

Applying these global specifications to a single IU-shaped module, the objectives and constraints for the parametric search could be defined. Satisfaction of the constraints establishes the validity of the design.

\section{B. Parametric search}

Because of the absence of the fast but accurate analytical model and derivation of the objective function(s) it is impossible to perform the multi-objective optimization procedure. A parametric search is carried out to evaluate how the behavior of the IU-shaped actuator varies dependent on the deviation of the geometrical parameters-design variables. Instead of performing the search in the whole multidimensional space of design variables, the space is divided into several subspaces of two-three dimensions and the length of each dimension was bounded by the side constraints, determined from specifications. The parametric search is made by means of FEM modeling, utilizing Ansoft Optimetrics software.

Several types of characteristics are used to evaluate the improving or declining of the performance. Position stiffness is a dependence of the suspension force $F_{z}$ on a displacement of the rotor bar from the central position along the $z$-direction (zdispl). Position stiffness characteristic is determined for the case of non-excited suspension and propulsion coils. Current stiffness is a dependence of the suspension force $F_{z}$ on a value of the magnetomotive force (MMF) of the suspension coil $\left(N^{*} I s u s p\right)$. Besides, current stiffness characteristics built for different values of the current in the propulsion coils elucidate the cross-coupling effect between the suspension and propulsion directions. Quasi-efficiency characteristics show the MMF of the suspension coils that is sufficient to produce $7.5 \mathrm{~N}$ along the suspension $z$-direction to compensate gravity force on the rotor. The aim of the parametric search is to find the geometry which provides the decreased position stiffness, increased current stiffness and as little cross-coupling effect as possible, while taking into account the efficiency of the suspension.

The following main design variables form the designspace:

- $\quad$ rotor bar height (along the $z$-direction);

- $\quad$ rotor bar length (along the $x$-direction);

- $\quad$ air gap height (along the $z$-direction);

- $\quad$ stator bar height (along the $z$-direction);

- $\quad$ stator bar width (along the $y$-direction);

- clearance between the stator bars (along the $y$ direction);

- $\quad$ PM height (along the $z$-direction);

- $\quad$ PM width (along the $y$-direction);

- $\quad$ PM length (along the $x$-direction).

For every vector of design variables the next current variables were used to obtain the desired characteristics:

- displacement of the rotor bar along the $x$-direction from the central position ( $x$ displ);

- displacement of the rotor bar along the $x$-direction from the central position (zdispl);

- $\quad$ MMF of the suspension coils ( $\left.N^{*} I s u s p\right)$;

- $\quad$ MMF of the propulsion coils ( $N^{*}$ Iprop);

and the following outputs were monitored:

- value of the flux density at the center of the rotor bar, T;

- value of the flux density at the nearest to the PM part of the stator bar, $\mathrm{T}$;

- $\quad x$-component of the total force on the rotor bar, $\mathrm{N}$;

- $z$-component of the total force on the rotor bar, N.

Fig. 10 and Fig. 11 show examples of the calculated position and current stiffness characteristics for the crosssection of the stator bar $14 \times 14 \mathrm{~mm}^{2}$. In Fig. 12 examples of the quasi-efficiency characteristics are plotted. 


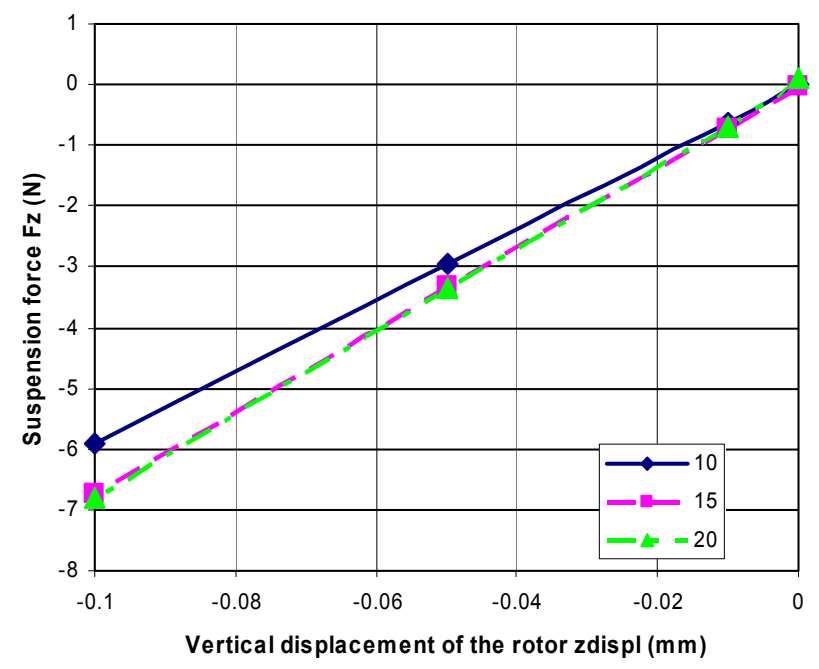

Figure 10. Position stiffness $F z(z)$ for the stator bar with cross-section of $14 \times 14 \mathrm{~mm}^{2}$ and clearance between the stator bars $(10,15,20 \mathrm{~mm})$.

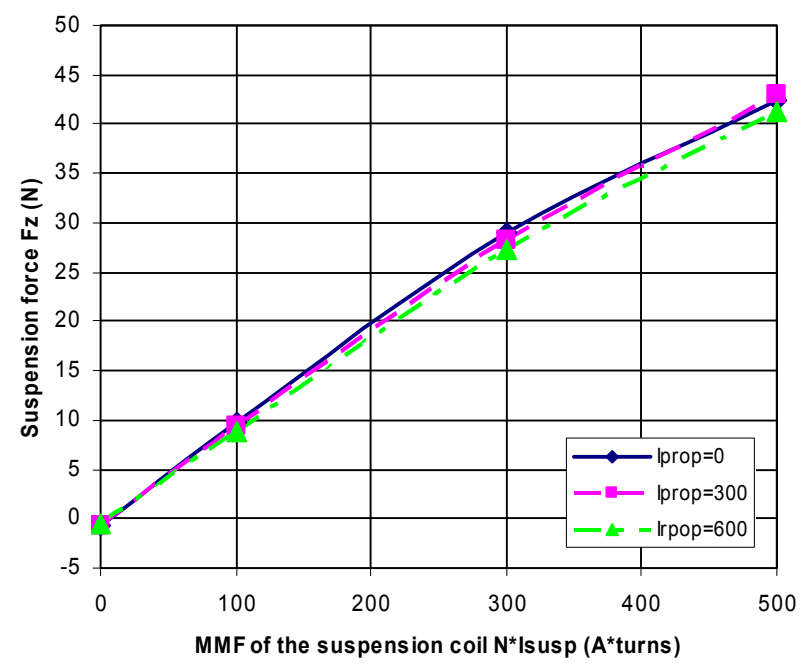

Figure 11. Current stiffness $F z\left(N^{*} I s u s p\right)$ for the stator bar with cross-section of $14 \times 14 \mathrm{~mm}^{2}, z d i s p l=0.01$ and clearance between the stator bars $15 \mathrm{~mm}$ for different values of MMF (NIprop) in propulsion coils.

As a result of the parametric verification, the initial geometry of the IU-shaped module was modified according to the above mentioned aim of the search. This geometry will be further checked by measurements on the set-up.

\section{EXPERIMENTAL SET-UPS}

Together with the finite element analysis several experimental setups were constructed to validate the performance IU-actuator. Only the 2 DOF set-ups were developed, integration into a 6 DOF system will commence when the desired performance is achieved with a 2 DOF system.

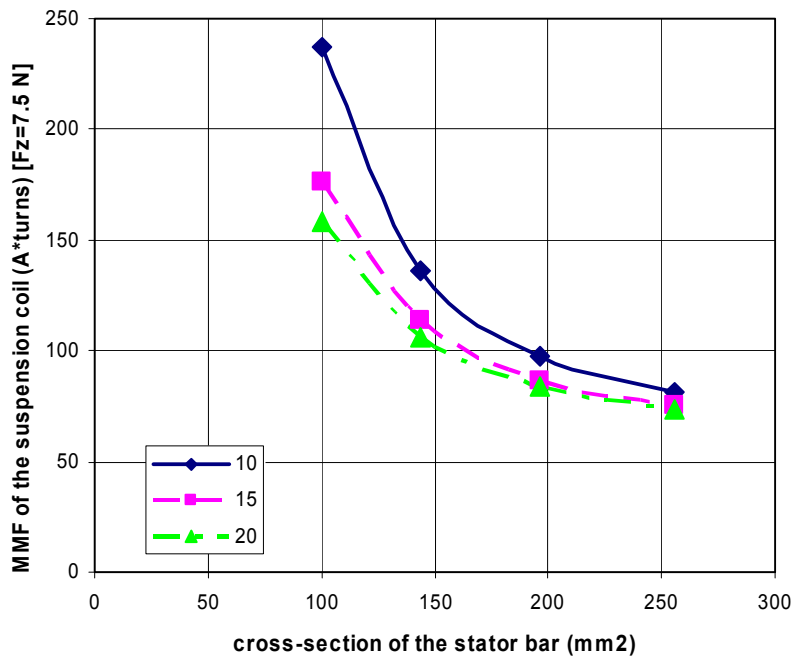

Figure 12. Quasi-efficiency characteristics for different values of the crosssection of the stator bars and different clearances between the stator bars $(10$, $15,20 \mathrm{~mm})$.

The first experimental set-up was constructed at the group of Advanced Mechatronics at Delft University of Technology [2], [5]). The goal of this first set-up was to validate the static performance of an IU-module. The static performance characterized by the forces on the rotor, due to its position and the currents through the different actuation coils. These forces were measured using strain gage sensors. The stator and rotor bars of this first IU-module were constructed using laminated iron. In Fig. 13 the measured and simulated force versus suspension position are shown.

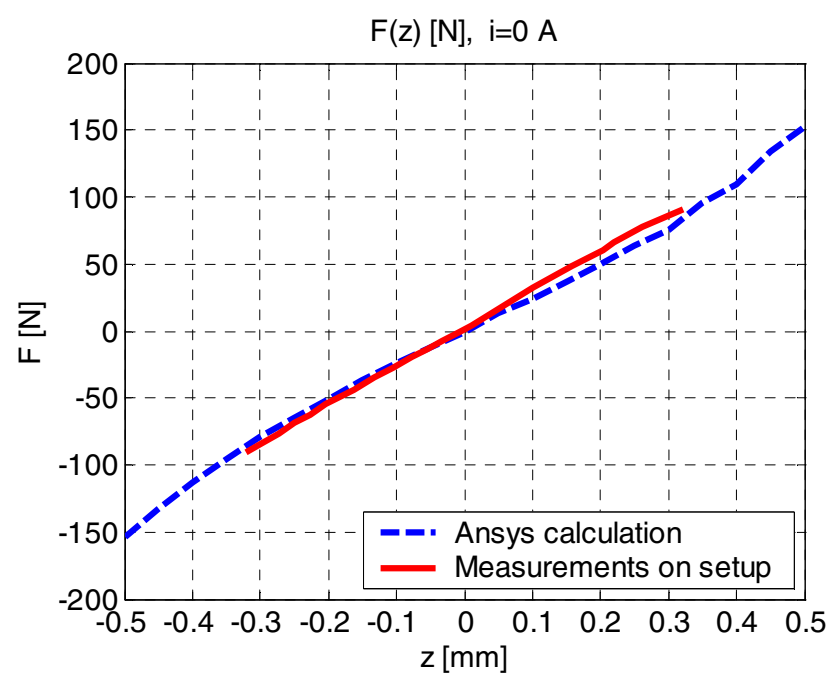

Figure 13. Force in the z-direction on the rotor versus the air gap position

To make the IU-module work dynamically sensors and an air bearing were added to the static setup. The air bearing constrains the four degrees of freedom not actuated by the IUmodule. The position sensors are used to measure the suspension and propulsion position. These sensors signals are 
fed back through a digital controller. Fig. 14 shows a drawing of the full dynamic setup.

The realized control bandwidths for suspension and propulsion are $180 \mathrm{~Hz}$ and $60 \mathrm{~Hz}$ respectively. The achieved resolution for suspension was 1 micrometer suspension and 0.3 micrometers for propulsion. The limitations in bandwidth and resolution do not originate in the IU-module itself, but in the sensors and air bearing surrounding it.

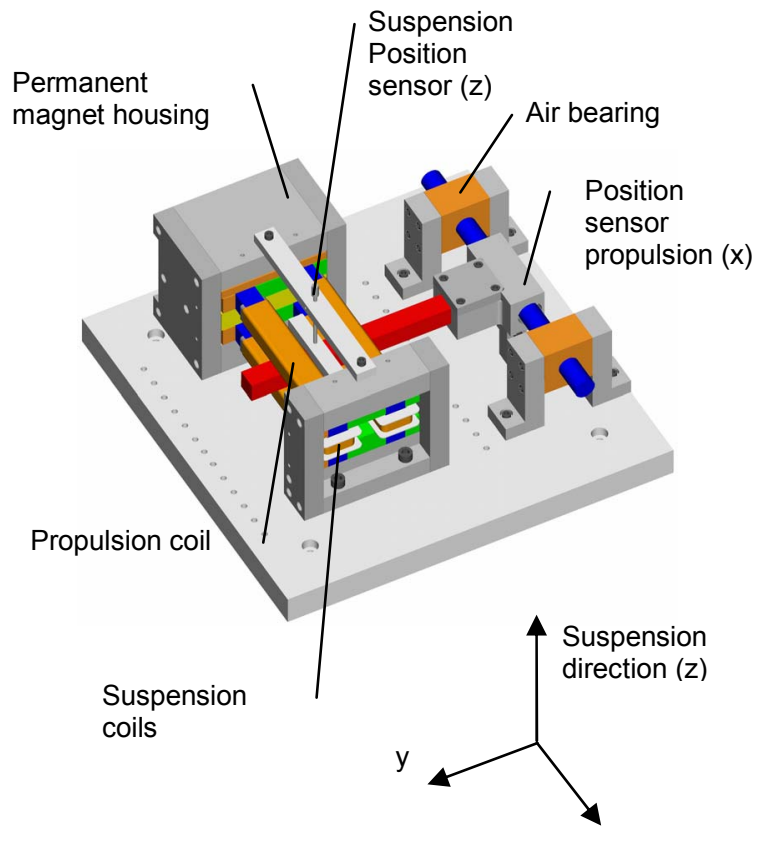

Propulsion direction $(\mathrm{x})$

Figure 14. Dynamic experimental setup

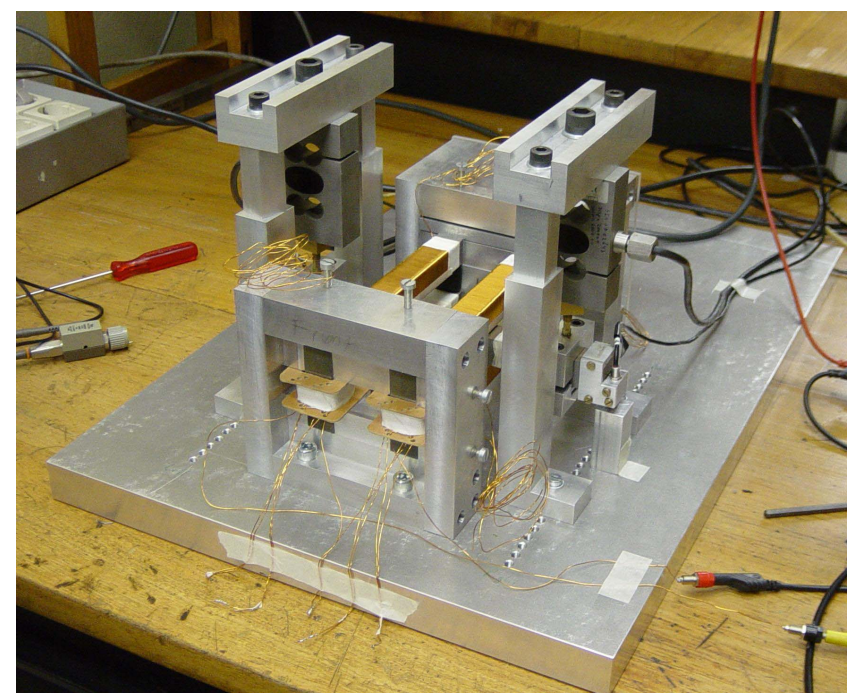

Figure 15. An experimental mechanical set-up with installed IU-shaped electromagnetic module and two force bridges for static suspension force measurements.
Although the performance of the IU-module was satisfactory, the used materials in the IU-module were not optimized. To evaluate the characteristics of different materials a new static experimental setup (Fig. 15) was developed. In this experimental setup the laminated stator and rotor bars were replaced with the bars made of SMC materials (Somaloy 500). Fig. 16 shows the static force measurements results for the SMC set-up. The first and last steps (within the wide range of the measurement points in Fig. 16) are characterized by "hooks" - the rotor rests on the stator bars. For the measurements with two force bridges, an equal air gap clearance of $0.25 \mathrm{~mm}$ is shown for both directions (the air gap clearance is $0.52 \mathrm{~mm}: 1.1 \mathrm{~mm}$ total air gap height minus 0.58 $\mathrm{mm}$ propulsion coil diameter with insulation).

From the results, obtained from the experimental setups, it has become clear that the IU-module can be used in 6 DOF nanometer-accuracy setup. A new optimized geometry has been developed using the techniques described in the previous sections. The dimensions of the IU-module were modified to fit with the requirements for the 6 DOF system as mentioned in the previous section. Table II shows the dimensions of this new geometry. The important feature of the new geometry results in less cross-sections and lengths of the stator and rotor bars and sizes of the PMs, that consequently leads to the significant reduction in weight and volume of the total structure.

TABLE II. IMPROVED GEOMETRY PARAMETERS OF THE IU-MODULE

\begin{tabular}{|c|c|}
\hline 4 stator bars & $15 \times 15 \times 100 \mathrm{~mm}^{3}$ (each) \\
\hline 1 rotor bar & $10 \times 10 \times 85$ \\
\hline 2 suspension coil cores & $15 \times 15 \times 12$ \\
\hline Air gap height & $1 \mathrm{~mm}$ \\
\hline Permanent magnets & $36 \times 15 \times 10$ \\
\hline
\end{tabular}

First, a new 2 DOF prototype will be constructed to evaluate the performance of the evaluated geometry. If this performance is satisfactory, the integration into a 6 DOF system will commence.

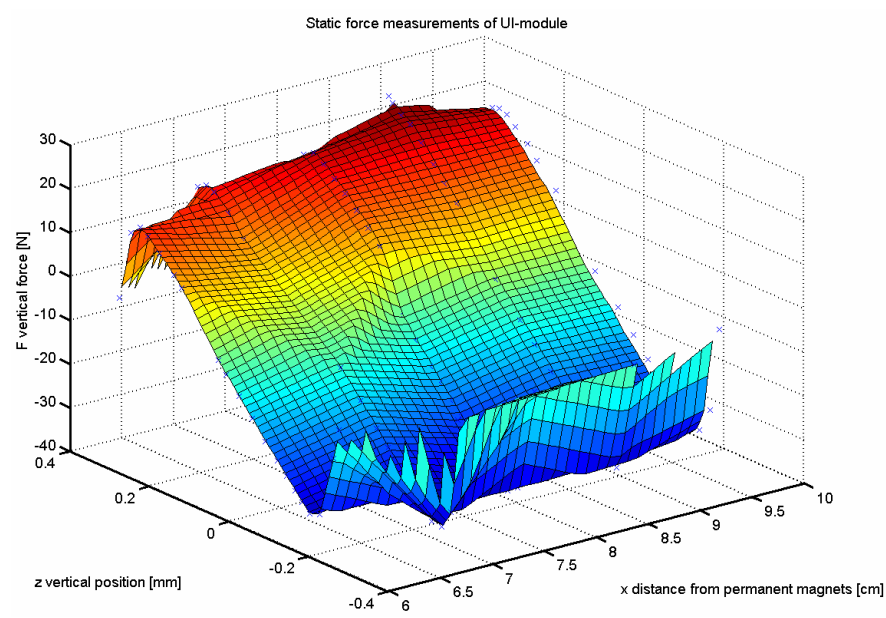

Figure 16. Static force measurement results of IU-module (the range of possible $z$-displacement is limited to $\pm 0.25 \div 0.3 \mathrm{~mm}$ due to the presence of the propulsion coils wounded around stator bars at physical test set-up). 


\section{CONCLUSIONS}

The focus of this paper has been to analyze the electromagnetic and electromechanical behavior of the novel actuator. The analytical and 3D FEM magnetostatic models of the IU-shaped actuator have been developed to predict the field quantities and force distributions of the topology under study. Both models allow computing the forces acting on the rotor, as the functions of its position and the coil currents. A set of force calculations (using analytical models and FEM models) has been performed and results have been compared with measurements. It has been shown that the current analytical model is not sufficiently accurate (relative errors are in the range of 15 to $25 \%$ ) and can not be used for synthesis of the actuator structure. Only FEM model can describe the important features of the actuator performance caused by variation of parameters and capture the complexity of the physical phenomena in the system, such as position and current stiffness characteristics.

The parametric evaluation of the actuator geometry, and force quasi-optimization study have been performed by means of the FEM modeling (Ansoft Optimetrics software). As a result, the set of the design variables is identified for future multiobjective optimization procedure and a new modified geometry is proposed. A new test set-up will be built to verify this geometry.

\section{ACKNOWLEDGMENT}

The authors are grateful to Dutch "Technologiestichting STW" for granting the project on "Six Degree-of-Freedom
Contactless Slide System" and acknowledge the valuable support (with soft magnetic composites) from the Höganäs AB, Sweden.

\section{REFERENCES}

[1] A. Molenaar, "A novel Planar Magnetic Bearing and Motor Configuration applied in a Positioning Stage", Ph.D. dissertation, Dept. of Mechanical Eng., TUDelft, 2000.

[2] S.C.L. van de Ven, "Design and Realization of an IU-module", MSc. thesis, Dept of Mechanical Eng., TUDelft, Aug. 2003.

[3] User Guide, Maxwell 3D, version 9.0, Ansoft Co, 2002.

[4] Herbert C. Roters, Electromagnetic Devices, John Wiley \& Sons, Inc, New York, 1958.

[5] D.A.H. Laro, S.C.L. van de Ven, J.W. Spronck, A.V. Lebedev, E.A. Lomonova, B. Dag, "A Linear Magnetic Bearing with Integrated Long Stroke Propulsion - Design and Realization of an IU-module", PEMD conference Proceedings, UK, CD-rom, pp.1-5.

[6] P. Jansson, M. Persson, A.G. Jack and B.C. Mecrow, "Powdered soft magnetic materials for medium frequency applications," Proc. Soft Magnetic Materials SMM'96, February 1996.

[7] Jimmie J. Cathey, Electric Machines: Analysis and Design Applying MATLAB ${ }^{\circledR}$, McGraw-Hill Higher Education, Singapore, 2001.

[8] J.L. Coulomb and G. Meunier, "Finite Element Implementation of Virtual Work Principle for Magnetic or Electric Force and Torque Computation", IEEE Transactions on magnetics, Vol. Mag-20, N0. 5, September 1984, pp. 1894-1896.

[9] C.J. Carpenter, "Surface-Integral Method Of Calculating Forces On Magnetized Iron Parts", IEE Monograph No. 342, August 1959, pp.1928 .

[10] A.B.J. Reece and T.W. Preston, Finite Element Methods in Electrical Power Engineering, Oxford University Press Inc., New York, 2000. 